\title{
Mapping Free Educational Software Intended for the Development of Numerical and Algebraic Reasoning
}

\author{
Eliane Elias Ferreira dos Santos \\ Escola de Educação Básica - ESEBA \\ Universidade Federal de Uberlândia, Brazil \\ Aleandra da Silva Figueira-Sampaio \\ Faculdade de Gestão e Negócios - FAGEN \\ Universidade Federal de Uberlândia, Brazil \\ Gilberto Arantes Carrijo \\ Faculdade de Engenharia Elétrica - FEELT \\ Universidade Federal de Uberlândia, Brazil
}

\begin{abstract}
Educational software has significantly changed how mathematics is taught and learned. One challenge for educators is choosing the most appropriate software among numerous options. Therefore, we mapped free mathematics education software according to number and operation content. The study was carried out with public elementary school teachers (grades 6 - 9). The teachers watched a presentation on the features of each software type and filled out a checklist about the software and its content. The results showed that $63 \%$ of the 32 software titles were appropriate for developing numeric and algebraic reasoning. According to the teachers, these titles were appropriate for developing and consolidating concepts related to the number system, operations and properties of natural and whole numbers, numeric expressions, divisibility, prime numbers, decomposition into prime factors, GCD, LCM, operations with rational numbers in fraction and decimal form, comparison and operations on equivalent fractions, first degree equations, and first and second degree polynomial functions.
\end{abstract}

Keywords: Element school; Mathematic; Software; Number and operations; Algebra

\section{Introduction}

Every day we deal with data related to the weather, advertisements, percentages, account balances, debits, purchases, sales that demand arithmetic 
competence. This type of thought includes the ordered use basic mathematical operations, as well as the understanding of numerical calculation processes (Savion \& Seri, 2016), in addition to the ability to estimate quantities and evaluate the reasonableness of results.

These skills are built throughout elementary and middle school and encompass numerical and algebraic reasoning. According to curriculum guidelines (Brasil, 1998; National Council of Teachers of Mathematics [NCTM], 2000), students can develop these thought processes through various strategies including the exploration of learning situations that help them broaden and consolidate their understanding of numbers, in various numerical sets, using social, mathematical, and historical contexts. Thus, problem-solving situations should allow students to expand on and consolidate their understanding of addition, subtraction, multiplication, division, exponents, and root operations while selecting and using different calculation procedures. Strategies should also include the ideas of proportionality and percentage calculations.

Studies have focused on the use of calculators (Ahn, 2001; Lee, 2006), concrete materials (Figueira-Sampaio, Santos, Carrijo \& Cardoso, 2013) and computers and software (Figueira-Sampaio, Santos, Carrijo \& Cardoso 2012) in education to assist in the development of mathematical skills that involve mastery of numbers and calculations. The use of digital resources in teaching can favour positive attitudes when learning mathematics (Chen, Lee \& Hsu, 2015). There exists considerable qualitative evidence concening the benefits of computers and software in the education of mathematics: an increase in critical thought and in the ability to solve problems (Condie, Munro, Seagraves \& Kenesson, 2007; Keong, Sharaf, \& Daniel, 2005); an increase in motivation, interest and participation (Keong et al., 2005; Neurath \& Stephens, 2006; Reynolds \& Fletcher-Janzen, 2007); encourage collaboration which favours dialogue and working in teams (Balanskat, Blamire \& Kefala, 2006; Reynolds \& FletcherJanzen, 2006); improvements to basic abilities, such as reading, writing and calculating; improvements to behaviour and attention during the class (Balanskat et al., 2006); better retention of knowledge (Reynolds \& FletcherJanzen, 2007).

While numerous software packages have been developed for education, the use of such material does not arrive into the classroom at the same proportion or speed. The selection and even finding accessible software may distance teachers and teaching practices from these educational resources According to FigueiraSampaio et al. (2012), the teachers choose the software through indications made by the teachers that used such in their teaching. Aimed at aiding in the choosing of software, as well as present the viable options of software in mathematics, the objective behind this work was to map free educational mathematics software for the development of concepts and procedures relevant to numeric reasoning and algebra. 


\section{Method}

The associated research was structured into two stages (Figure 1), these being classified as exploratory and descriptive. In the first stage bibliographic research was performed in order to carry out a survey of mathematical educational software. The search was performed using sites or promotional material in digital format. The selection of software was concluded from only available freeware, with online access of installation files that are available and developed for elementary school teaching in the 11 to 15 -year age range.

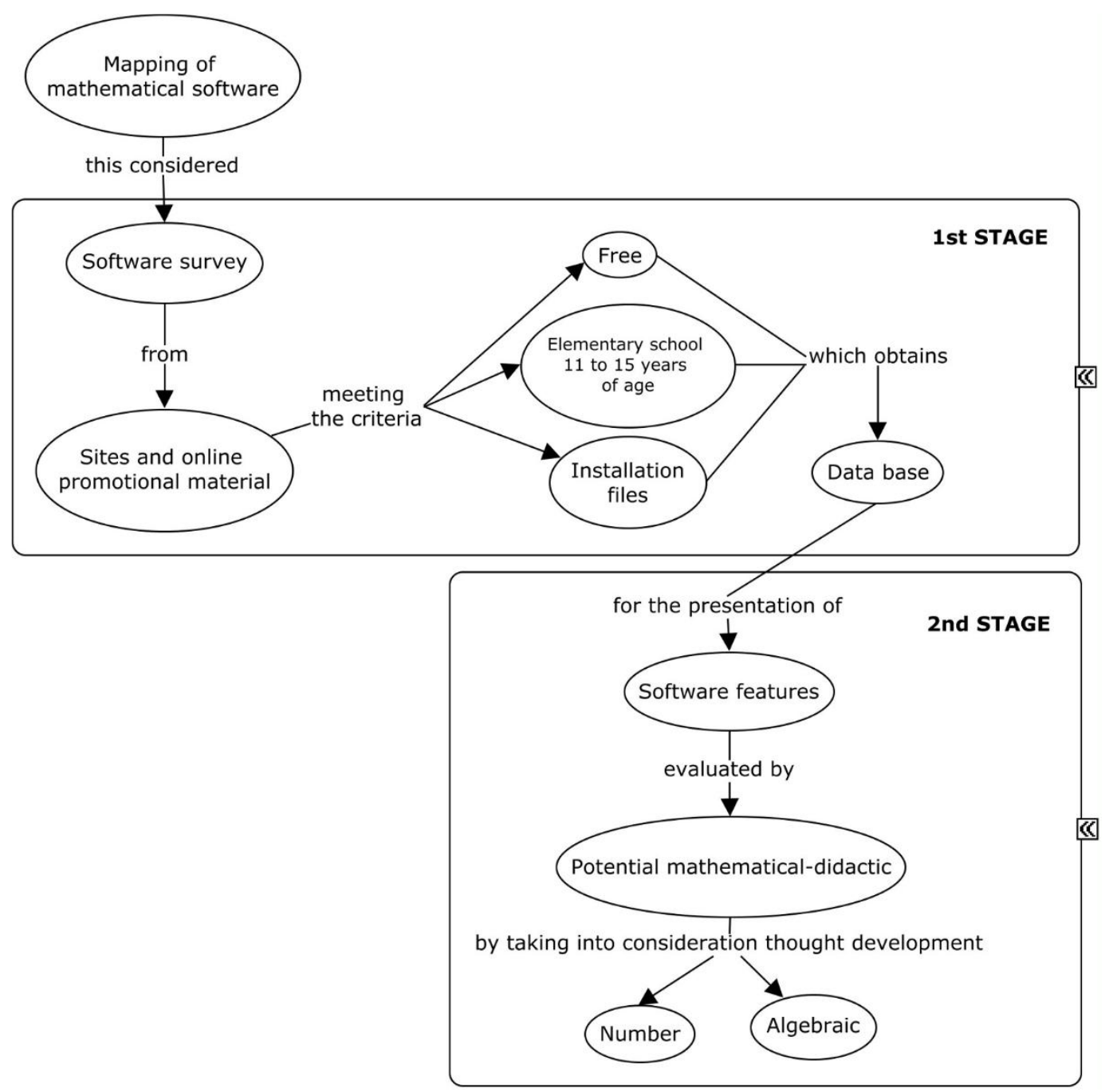

Figure 1: Stages of research.

In the second stage, two meetings were held with teachers of mathematics from the elementary levels, the objective being to identify possible content for the development of numeric and algebraic thought, which in turn could be used in the software programs. In total 34 Brazilian teachers from the public teaching sector participated in the study.

During these meetings, the software interface was projected through use of a projector and computer set up to evaluate the features from the didacticmathematical point of view. The features were demonstrated through providing 
examples, along with menu tabs and tools, buttons and on screen instructions. It was not possible in this set up that the teachers themselves explore the software.

The teachers received a checklist with specific math content for Number and Operations as well as Algebra at the beginning of each demonstration. The checklist was elaborated based on essential content from an elementary mathematical teaching level (NCTM, 2000).

\section{Results and Discussion}

During the survey of the all available freeware for the teaching of mathematics, identification was made as to 32 programs with features that contribute to the teaching and learning of mathematics at the elementary level (Table 1). From this number, 59\% need to be downloaded and installed onto the computer and $41 \%$ were accessed through browsers.

According to the teacher group, $63 \%$ of the free software could be used to teach elementary school content involving numbers and related operations and elementary concepts of algebra (Figure 2). Mathematics at this level is centered on numerical concepts and operations (Dunphy et al., 2014; Lemonidis \& Kaiafa, 2014; Mohamed \& Johnny, 2010; NCTM, 2000; Thanheiser, Whitacre \& Roy, 2014) and problem solving (Lemonidis \& Kaiafa, 2014; Ontario Ministry of Education, 2005; Thanheiser et al., 2014). Students use operations and properties involving different types of numbers to solve various problems. Algebraic representations also contribute to the students' experiences with numbers (NCTM, 2000). Students encounter different sets of numbers (natural, whole, rational, and irrational) progressively and according to necessity as their problem solving requirements evolve.

The set of natural numbers is the most fundamental mathematical object (Lengnink \& Schlimm, 2010). These numbers arose at the beginning of ancient civilizations and are used today to solve problems requiring counting, ordering, and coding (Debnath \& Basu, 2015). To solve problems of this type, students need to understand both the meanings and properties of the numbers. The teachers identified the following software packages as appropriate for this objective: Árvores Algébricas (Algebra Trees), Butterflies, Circle 21 and 99, Criba de Eratóstenes, Diffy, Roman Numbering, Prime Numbers, Tic Tac Go, and Tux of Math Command.

Students consolidate their understanding of the meaning of numbers by exploring different symbolic representations of numbers and the relationships between them (Ontario Ministry of Education, 2005). Writing and manipulating numerals contributes to a more comprehensive understanding of their properties (Lengnink \& Schlimm, 2010). Thus, it is common to work with both Roman numerals and the Hindu-Arabic numbering system.

Roman numerals were widely used throughout the Roman empire, but are still used for numbering centuries, book chapters, and the faces of some analog clocks. The group of teachers recommended the Roman Numbering software for 
addressing relationships between two numbering systems. The objective of this software is the conversion of Western-Arabic numerals into Roman numerals and consists of two players taking turns proposing challenge problems to one another. The first player presents a Western-Arabic numeral between 1 and 1000 and the second player converts the number to a roman numeral.

Table 1: List of free educational software for mathematics and the percentage of teachers that identified the potential of software for developing a numeric and algebraic thinking ( $n=$ number of teachers that answered the checklist for software).

\begin{tabular}{|c|c|c|}
\hline Software & Internet address & $\%$ teachers $(\mathrm{n})$ \\
\hline $\begin{array}{l}2 \text { Árvores Algébricas } \\
\text { (Algebra Trees) }\end{array}$ & $\begin{array}{l}\text { http://www2.mat.ufrgs.br/edumatec/atividades } \\
\text { _diversas/maquina/arvore.htm }\end{array}$ & $100(24)$ \\
\hline 1,2 Butterflies & http://nautilus.fis.uc.pt/mn/ & $100(22)$ \\
\hline 1,2 C.a.R - Compass and & http://car.rene- & - \\
\hline Ruler & grothmann.de/doc_en/index.html & \\
\hline 1,3 Circle 0, 3, 21, 99 & http://nlvm.usu.edu/en/nav & $100(18)$ \\
\hline $\begin{array}{l}{ }^{3} \text { Criba de Eratóstenes } \\
\text { (Sieve of Eratosthenes) }\end{array}$ & http://nlvm.usu.edu/es/nav & $100(13)$ \\
\hline 1,3 Diffy & http://nlvm.usu.edu/en/nav & $100(4)$ \\
\hline 1,2 Dr Geo & http://www.drgeo.eu/download & - \\
\hline 1,3 Fractions-Equivalent & http://nlvm.usu.edu/en/nav/ & $100(20)$ \\
\hline 1,2,3 GeoGebra & http://www.geogebra.org/cms/download & $48(25)$ \\
\hline${ }^{1}$ Geometry 2.1 & $\begin{array}{l}\text { http://www.somatematica.com.br/zips/geometr } \\
\text { y1.zip }\end{array}$ & - \\
\hline 1,2 Geonext & http://geonext.uni-bayreuth.de/ & $8(24)$ \\
\hline 1,2,3 GrafEQ & ftp://ftp.peda.com/grafeq_setup.exe & $100(2)$ \\
\hline 1,3 Grapher & http://nlvm.usu.edu/en/nav & $96(27)$ \\
\hline 1,2,3 Graph & http://www.padowan.dk/download/ & $80(15)$ \\
\hline${ }^{1}$ MathGV & http://www.mathgv.com/ & $90(21)$ \\
\hline 1,2 Prime Numbers & http://nautilus.fis.uc.pt/mn/ & $100(17)$ \\
\hline 1,2 Roman Numbering & http://nautilus.fis.uc.pt/mn/ & $100(18)$ \\
\hline 2 Polígonos (Polygons) & $\begin{array}{l}\text { http://www.somatematica.com.br/softw/poligo } \\
\text { nos.zip }\end{array}$ & - \\
\hline 1,3 Poly & ftp://ftp.peda.com/poly32.exe & - \\
\hline 1,3 Percentages & http://nlvm.usu.edu/en/nav & $100(13)$ \\
\hline 2 Raízes (Roots) & $\begin{array}{l}\text { http://www.somatematica.com.br/zips/raizes.zi } \\
\text { p }\end{array}$ & $100(17)$ \\
\hline 1,3 Pythagorean Theorem & http://nlvm.usu.edu/en/nav & - \\
\hline${ }^{1}$ Shape Calculator & $\begin{array}{l}\text { http://www.somatematica.com.br/softw/Shape } \\
\text { Calc.zip }\end{array}$ & - \\
\hline 1,2,3 SpeQ Mathematics & http://www.speqmath.com & $100(4)$ \\
\hline 2 Tangram 32 & https://rachacuca.com.br/jogos/tangram-32/ & - \\
\hline 1,2 Pitagoras' Theorem & http://nautilus.fis.uc.pt/mn/ & - \\
\hline 1 Tic Tac Go & $\begin{array}{l}\text { http://www.fisme.science.uu.nl/toepassingen/0 } \\
\text { 3088/toepassing_wisweb.en.html }\end{array}$ & $100(3)$ \\
\hline 2 Triângulo (Triangle) & https://sites.google.com/site/softwaretriangulos & - \\
\hline $\begin{array}{l}2 \text { Trigonometria } 1.1 \\
\text { (Trigonometry) }\end{array}$ & $\begin{array}{l}\text { http://www.somatematica.com.br/zips/trigono. } \\
\text { zip }\end{array}$ & - \\
\hline 1,2,3 Tux of Math Command & $\begin{array}{l}\text { https://tuxmath.br.uptodown.com/windows/do } \\
\text { wnload }\end{array}$ & $100(3)$ \\
\hline 1,2,3 Wingeom & http://www2.mat.ufrgs.br/edumatec & - \\
\hline 1,2,3 Winplot & http://www2.mat.ufrgs.br/edumatec & $89(19)$ \\
\hline
\end{tabular}

Some Languages: ${ }^{1}$ Inglês, ${ }^{2}$ Portuguese, ${ }^{3}$ Spanish 


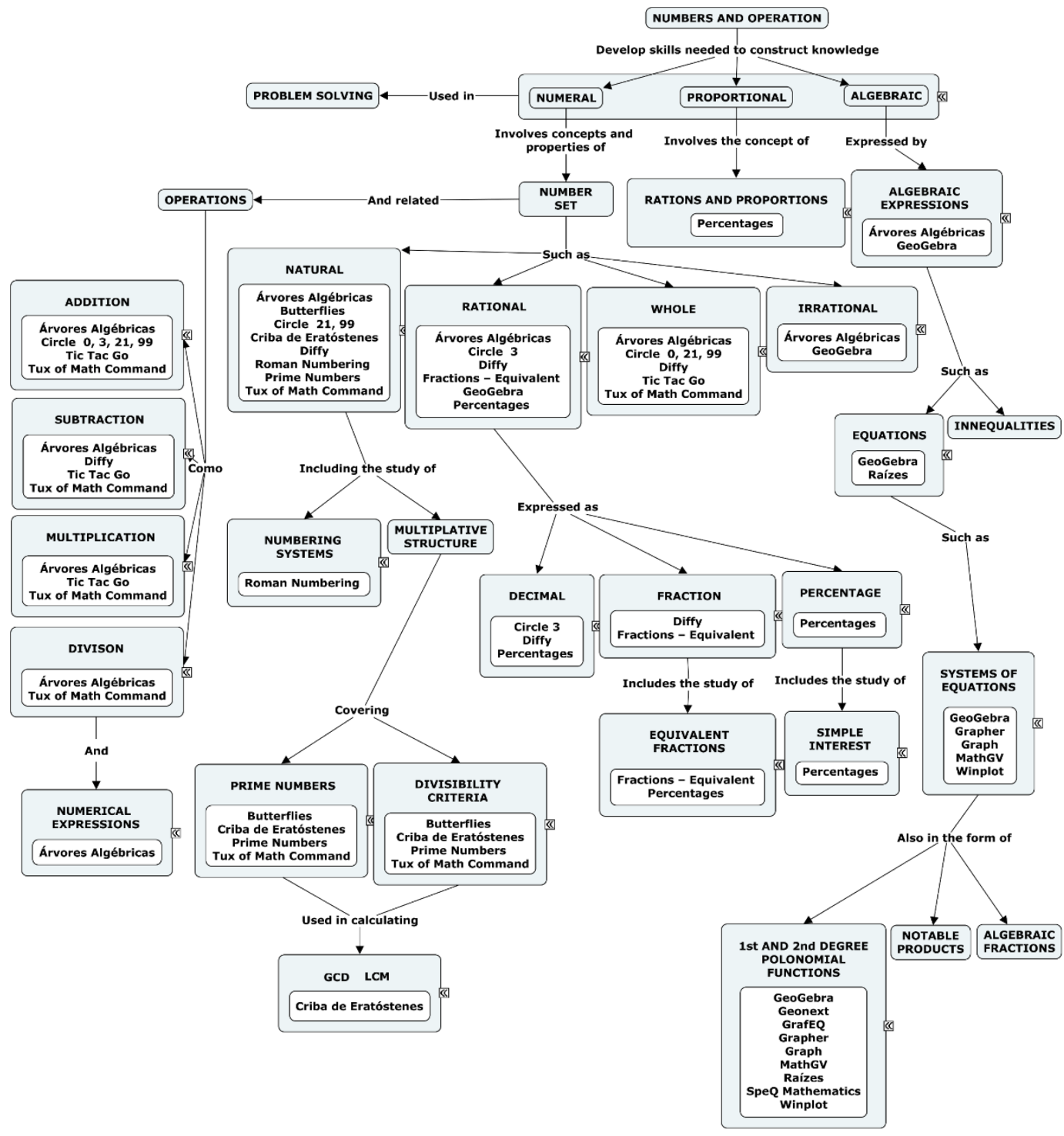

Figure 2: Software mapping by Numbers and Operations and Algebra.

Mathematics curricula for elementary and middle schools include the study of the multiplicative structure of natural numbers (Brasil, 1998; NCTM, 2000). This knowledge is applied at various levels and in diverse areas of mathematics (Dias, 2005). Understanding the concept of the multiplicative structure includes experience with the representation of natural numbers as the product of prime numbers. This construction, in turn, includes the concepts of the greatest common divisor (GCD) among two or more natural numbers, the least common multiple (LCM), and the ability to recognize and justify divisibility relationships (Brown, Thomas \& Tolias, 2002).

Divisibility criteria are important tools for determining whether a quotient is exact or not, without needing to know the quotient (Brown et al., 2002). Usually, a simple calculation is made with the digits (Crandall \& Pomerance, 2005; Peretti, 2015). For prime numbers, it is sufficient to recognize that the number is only divisible by one and the number itself. The problem of distinguishing 
between natural prime numbers and compound natural numbers and of decomposing compound numbers into their prime factors is considered one of the most important and useful in arithmetic (Debnath \& Basu, 2015).

The teachers identified the following software as appropriate for developing content related to prime numbers and divisibility criteria: Butterflies, Criba de Eratóstenes, Prime Numbers and Tux of Math Command. These software packages provide activities in which students actively participate in building understanding of operations and calculation techniques. Each software with its own features.

In the software Butterflies, quick animations and actions are necessary on the part of the user. The Butterflies package displays numerous butterflies, labeled with numbers, that move around the screen. The student needs to use mouse clicks to capture the butterflies in the shortest time possible. Three different tasks with primes and multiples can be used to capture the butterflies. Butterflies with prime numbers are captured in the first task, butterflies with numbers that are multiples of 3 in the second task, and in the third task, those with numbers that are even when multiplied by 3 .

The software Criba de Eratóstenes reproduces the methodical process of the Eratosthenes sieve. The method for finding a finite number of prime numbers greater than one (Debnath \& Basu, 2015). The user interface presents a cell grid (10xn), with natural numbers greater than 1 . Students select the desired number of rows and then choose whether or not to display the multiples of the number chosen from the numbers on the screen. This functionality allows educators to not only explore prime numbers but also the calculation of the least common multiple between two natural numbers from the complete set of multiples. The option "Quitar Múltiplos" (Remove Multiples) eliminates the multiples of the natural numbers successively selected by the student. Thus, prime numbers between 1 and $\mathrm{n}$ are obtained after a finite quantity of selections.

In the software Prime Numbers, the result for right and wrong answers is presented to the user without any type of animation. The Prime Numbers application is used to identify the prime numbers among the first 25 (or 100) natural numbers. Selections are made using two on-screen buttons. The "Give $\mathrm{Up}^{\prime \prime}$ button shows the prime numbers within the natural numbers selected by the student. Counters for correct and incorrect choices are updated after each selection.

Rational numbers are used to solve problems involving whole/part relationships, quotients, ratios, proportions, scales, percentages, rates, indices and simple interest. The concept of rational numbers is one of the most important and complex in mathematics education at the elementary/middle school level (Bezuk \& Biek, 1993; Lemonidis \& Kaiafa, 2014). Understanding this type of number is important in school and in everyday life (Van Hoof, Verschaffel \& Van Dooren, 2015). Rational numbers can be written in many ways including fractions, decimals, percentages, indices, and rates 
(Beyranevand, 2014). Learning these numbers involves not only understanding each representation, but also transforming one format into another (e.g., fractions to decimals, percentages to fractions).

Understanding and correctly using decimal numbers is essential to understanding more advanced mathematical topics (Isotani, MClaren \& Altaman, 2010) and daily activities involving measures and money. The decimal form of rational numbers has been a significant source of difficulty in mathematics education (Stacey et al., 2001).

Sadi (2007) highlights the mistakes made by students in performing operations with decimal numbers. The software Circle 3, Diffy, and Percentages were recommended by the teachers as potential aids for improving fluency with operations using decimal numbers. These applications provide activities that involve the addition, subtraction, and relative visualization of decimal numbers, respectively. The Georgia Department of Education (2015) defines fluency as the ability to perform procedures in a flexible, accurate, efficient, and appropriate manner.

Proportional thinking, which includes an understanding of ratios, proportions, and proportionality, is necessary in mathematics, science, and practical applications (Lundberg, 2011; Ontario Ministry of Education, 2012; Silvestre \& Ponte, 2012). It is important to use a variety of experiences involving proportional reasoning and to encourage students to make conjectures, create rules, and generalize learning (Adjiage \& Pluvinage, 2007; Ontario Ministry of Education, 2012). In math education, some concepts are interconnected to aid in the construction of proportional thinking. Understanding rational numbers in different forms is included in these concepts (Ontario Ministry of Education, 2012).

The teachers in our study group recommended the Percentages application not only works with decimal forms of rational numbers, but also helps build understanding of the concept and calculation of simple interest and the calculation of the fourth proportional. The software interface shows three text boxes representing unit, part, and percentage (Figure 3). The essence of proportional reasoning is the ability to consider numbers in relative rather than absolute terms (Ontario Ministry of Education, 2012). In this software, the value of an unknown is displayed by pressing the "Compute" button. Afterwards, a graphical representation of the result appears in a bar graph and a pie chart. The software thus encourages a comparison between an absolute value and its percentage or relative value.

Students struggle with the representation of numbers as fractions, which differs from the representation of natural numbers (Nunes \& Bryant, 2009; Stafylidou \& Vosniadou, 2004). The fraction is interpreted as a pair of integers and while students can usually write the fraction correctly, they are often unable to make a connection between a fraction and an integer (e.g. 5/5 and 1) (Amato, 2005). A 
fraction is a relation between numbers that represents their quantities but not their independent values (Nunes \& Bryant, 2009).

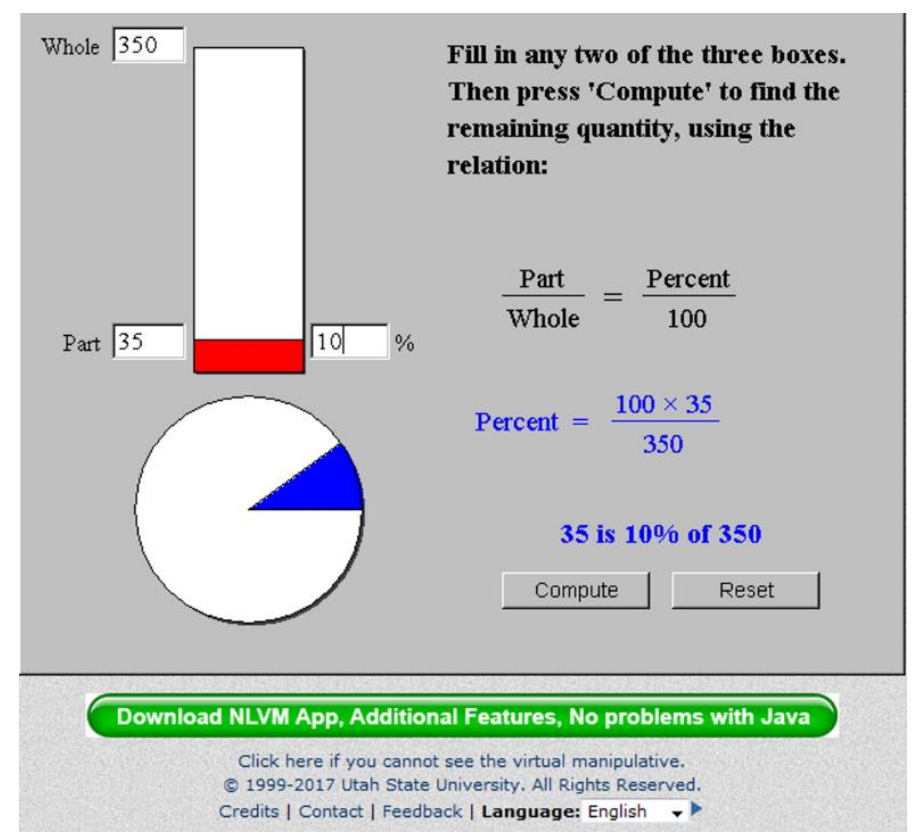

Figure 3: Percentages software.

The teachers in our study group recommended the Fractions-Equivalent application to build understanding of rational numbers in fractional forms. This software was chosen for its potential in developing skills related to the representation of fractions by dividing integers into congruent parts, by relating them to their symbolic numerators/denominators, and by visualizing a partwhole model. The software interface presents a diagram of the part/whole relationship and its respective fractional representation (Figure 4).

The relation established between these two forms of representation builds an understanding of the terms of the fraction. The student can then recognize that the denominator represents the number of parts into which the integer is divided and that the numerator is the number of parts that were considered when associating the diagram with the part / whole symbolic representation. Another important perception is the relationship between the number of parts and the relative size of these parts (Way, 2011). This involves the realization that the greater the number of parts that a shape is divided, the smaller the pieces become. Symbolically, this means that the greater the denominator, the smaller the parts. This knowledge can then be used to compare unit fractions.

The Fractions-Equivalent application randomly alternates the representation of an integer with shapes such as squares, rectangles, and circles. The software also responds to changes made in the diagram with corresponding changes in the symbolic form of the fraction. The great advantage of digital resources over other physical models is that different representations can be dynamically linked, allowing experimentation with cause and effect relationships that demonstrate the connections between different representations (Way, 2011). 


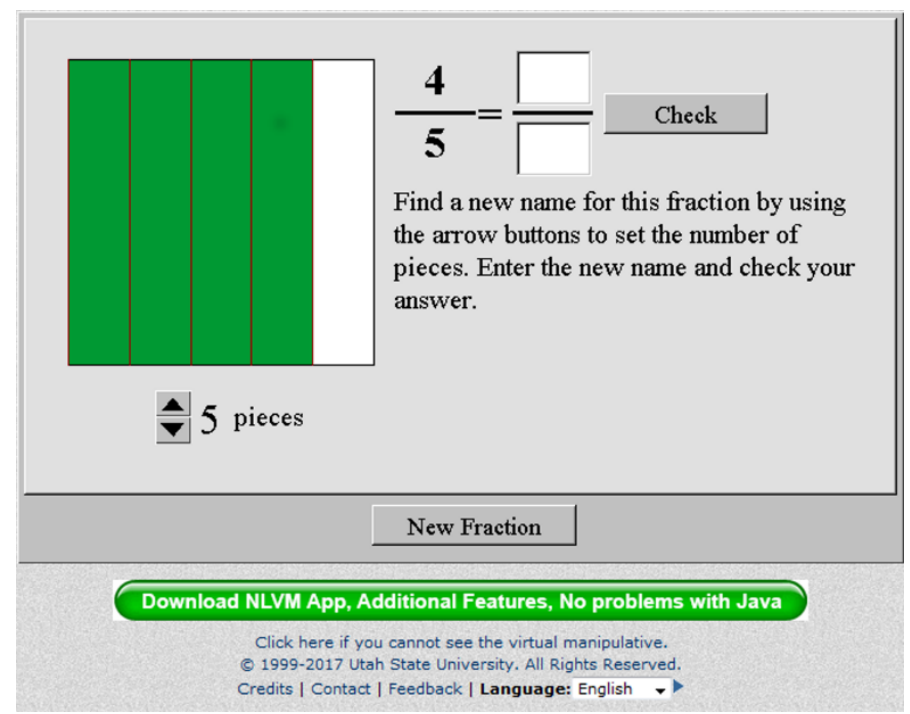

Figure 4: Fractions-Equivalent software.

The The Fractions-Equivalent application randomly alternates the representation of an integer with shapes such as squares, rectangles, and circles. The software also responds to changes made in the diagram with corresponding changes in the symbolic form of the fraction. The great advantage of digital resources over other physical models is that different representations can be dynamically linked, allowing experimentation with cause and effect relationships that demonstrate the connections between different representations (Way, 2011).

The concept of equivalent fractions is one of the most important abstract mathematical ideas for elementary/middle-school students to assimilate $(\mathrm{Ni}$, 2001). To build this skill, students must be able to determine equivalent fractions using part-whole models instead of mechanically using an algorithm that changes numerator and denominator through multiplication or division (Ontario Ministry of Education, 2014). According to the teachers in our study group, Fractions-Equivalent helps build this concept using part-whole models (Figure 4). The software allows students to change the number of parts by which an integer is divided without changing the initial division of the integer. This feature is extremely useful because it allows students to observe cause and effect (Way, 2011). Equivalent fractions are obtained when the lines that divide the original integer coincide with lines from the new division. After this step, students identify and write the new terms in text boxes and thus recognize the equivalent fractions. Pressing the "Check" button displays a message indicating whether the equivalence is correct or incorrect. Finally, the software also allows users to find multiple fractions that are equivalent to the original fraction.

Understanding the meaning and multiplicative structure of natural numbers and related operations is insufficient for solving problems in everyday situations involving impossible differences, debt, and the idea of opposing or symmetric quantities. These situations require integers (natural numbers plus negative numbers). The concept of integers emerged concurrently within the context of symbolic algebra used in solving algebraic equations (Brasil, 1998; Heeffer, 
2008). The set of integers and related operations present some challenges (Fuadiah, 2015; Heeffer, 2008; Kar \& Işik, 2015).

One of these challenges is how students perceive the logic of negative numbers and attribute meaning to negative quantities. Unlike the logic used with natural numbers, negative numbers make it possible to, for example, "add 6 to a number and get 1" or "subtract 2 from a number and get 9" (Brasil, 1998). The challenge of assigning meaning arises from the fact that students are surrounded by objects that are counted with positive numbers (Fuadiah, 2015). In addition, students interpret negative numbers as numbers having properties other than those of positive numbers, which leads students to difficulties with operations of type $a+(-b),-b+a$ and $a-(-b)$. The teachers in our study group chose Árvores Algébricas (Algebra Trees), Circle 0, 21 and 99, Diffy, Tic Tac Go and Tux of Math Command as software that could help build calculation skills with whole numbers and deal with the challenges highlighted in Brasil (1998) and Fuadiah (2015).

Although studies on the understanding of and the didactic approaches used for irrational numbers (Voskoglou \& Kosyvas, 2011) are rare, the topic is essential for rebuilding the concept of numbers so that it extends from the idea of rational numbers to include the set of real numbers (Sirotic \& Zazkis, 2007). Definitions of rational numbers at the elementary/middle-school level are strongly linked to representations (Zazkis \& Sirotic, 2010). Geometric representations are an indispensable teaching tool for understanding the concept of this type of number (Sirotic \& Zazkis, 2007). Lewis (2007) presents a construction based on the Pythagorean Theorem for the rational numbers $\sqrt{2}, \sqrt{3}, \sqrt{5}, \sqrt{6}$ and $\sqrt{7}$. In this construction, students are provided with a visual representation of the irrational number that they can then compare to the unit. Constructions such as this can be produced with the GeoGebra software (Figure 5), which was recommended by the teacher group for the visualization of irrational numbers. For Voskoglou and Kosyvas (2011), activities with geometric constructions have helped students improve their ability to construct immeasurable magnitudes and to represent irrational numbers on the real axis.

Extending the concept of numbers and gaining fluency with arithmetic operations are goals of elementary/middle school mathematics education (NCTM, 2000). Students need to develop their conceptual understanding and computational skills equally to develop operational fluency.

Conceptual understanding refers to an integrated and functional understanding of mathematical ideas (i.e., understanding more than just isolated facts and methods) (Kilpatrick, Swafford \& Findell, 2001), while computational skill refers to the ability to calculate accurately and efficiently (NCTM, 2000).

The teachers in our study group recommended Árvores Algébricas (Algebra Trees), Circle 0, 3, 21 and 99, Tic Tac Go and Tux of Math Command for developing addition skills and the same applications and Diffy for activities involving subtraction. Only Árvores Algébricas (Algebra Trees), Tic Tac Go and 
Tux of Math Command were recommended for multiplication. From the last three cited programs, Tic Tac Go is the only one that does not work with division.

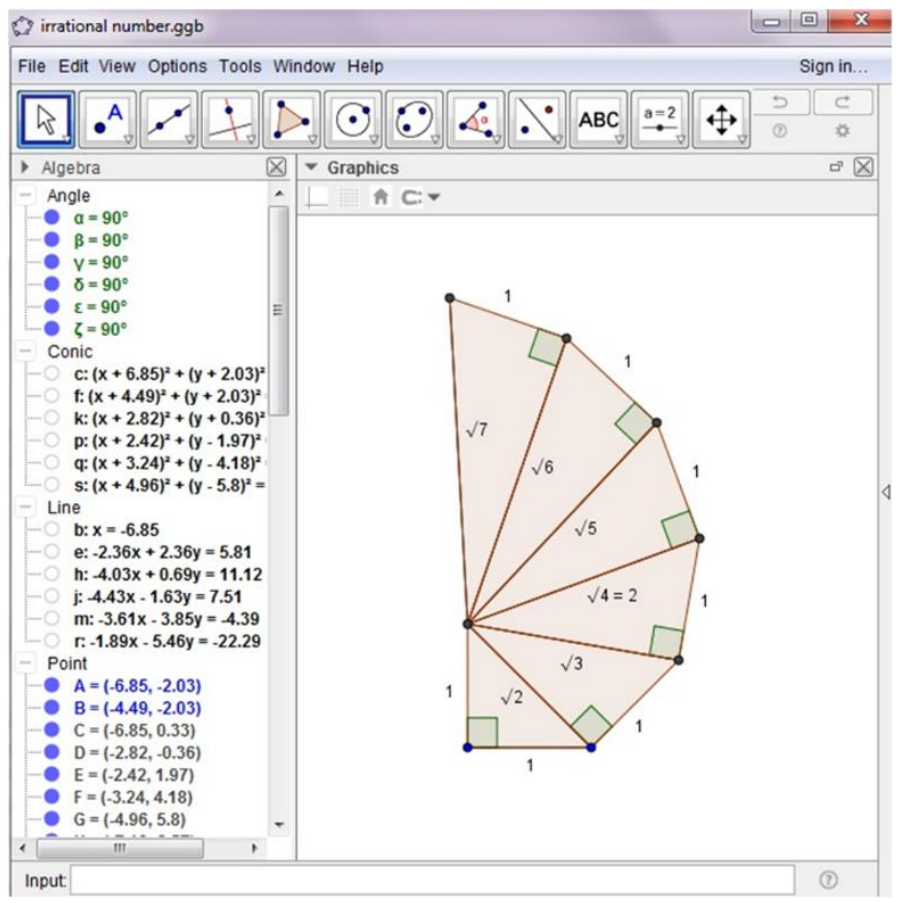

Figure 5: Construction in GeoGebra for the visualization of irrational numbers.

In Árvores Algébricas (Algebra Trees), students need to fill in text boxes and then drag and link them to each other with arrows denoting the order of operations. White boxes are used for data entry and output, while orange boxes are used for addition, subtraction, multiplication, division, and exponent operations. The software can be used to carry out operations with natural, rational, whole, and irrational numbers in the form of radicals.

The user interface in Circle 0 displays seven overlapping circles with integers spread out around the circles (Figure 6). The "New Game" button refreshes the numbers on the screen and in circles, or keeps the current problem in the circles. Students drag numbers into each circle such that the sum of the numbers is zero. If students choose correctly, the circle is highlighted red.

Circle 3, Circle 21 and Circle 99 are analogs of Circle 0. However, the algebraic sum of the numbers placed in each circle must be equal to 3, 21 and 99 respectively. In Circle 3, operations are performed on rational numbers in decimal form, while in Circle 21 and Circle 99 operations are performed on natural numbers.

Tux of Math Command can be played by more than one student and works with elementary arithmetic operations, including negative numbers, and "missing number" questions. The difficulty increases as the player progresses through the game. The goal is to destroy asteroids that are falling on igloos. To destroy the 
asteroids, the students must mentally solve the math problems displayed on each asteroid.

It is worth noting that mathematical knowledge includes proficiency with tools such as pencil and paper, technologies, and mental techniques (Seeley, 2005).

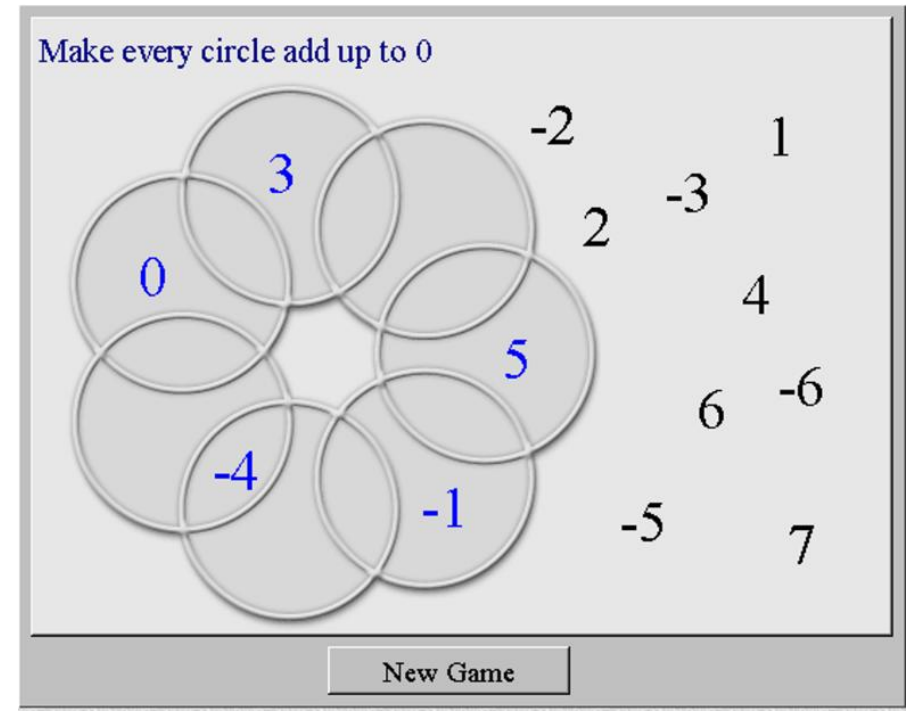

Figure 6: Circle 0 software.

The Diffy application is a virtual manipulator designed to encourage students to learn subtraction. The software simulates a board made up of five quadrilaterals, with integers placed on the vertices of the outermost shape. The remaining shapes are formed from the midpoint of each segment (Figure 7). The objective is to fill in the text boxes with the result of the difference between the largest and smallest number on the same line. The text box remains blank until the student answers the question correctly. This process is repeated until all text boxes are filled. The subtraction operations can be performed on natural, fractional, decimal, and monetary values.

With Tic Tac Go, version 3, users can explore addition, subtraction, and multiplication of whole numbers. Each cell contains an operation with integers. A number at the top of the grid corresponds to the result of the operation (Figure 8). Players scan the operations, perform an operation, and then select the cell that will produce the correct answer. The activity is concluded when the player can mark three correct squares in sequence, either horizontally, vertically, or diagonally. Competition between two students is also possible. The winner is the first to complete a correct sequence. In Tic Tac Go 5, the objective is to mark a sequence of five correct results in the grid.

As arithmetic problems become more complex, mental calculations and approximations are no longer sufficient to solve them. These more difficult problems must then be modeled algebraically. Thus, emphasis is given to using symbols to represent numbers and express mathematical relationships (Star et al., 2015). Previous experience with numbers and their properties are fundamental for working with algebraic symbols and expressions, which are 
elements of mathematical modeling (NCTM, 2000). Solving these types of problems allows students to develop their capacity to generalize and deepen their understanding of the relationships between patterns and algebra (Ontario Ministry of Education, 2013). The systematic use of symbols to express quantitative and structural relationships (i.e. representation) allows students to solve problems (Smith \& Thompson, 2007). This context allows mathematical language and ideas to acquire meaning. Algebraic reasoning provides the basis for the development and understanding of abstract mathematics (Ontario Ministry of Education, 2013; Star et al., 2015). Equations and systems of linear equations are used to represent, analyze, and solve a variety of problems (Common Core State Standards Initiative [CCSSI], 2010).

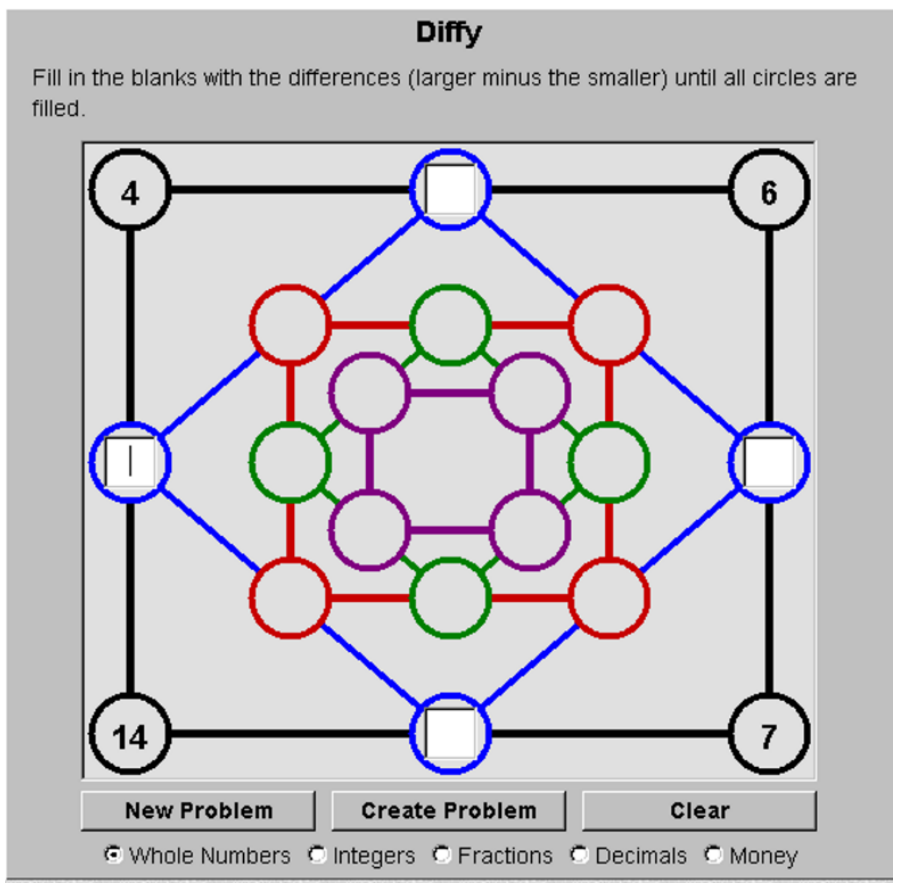

Figure 7: Diffy software. 


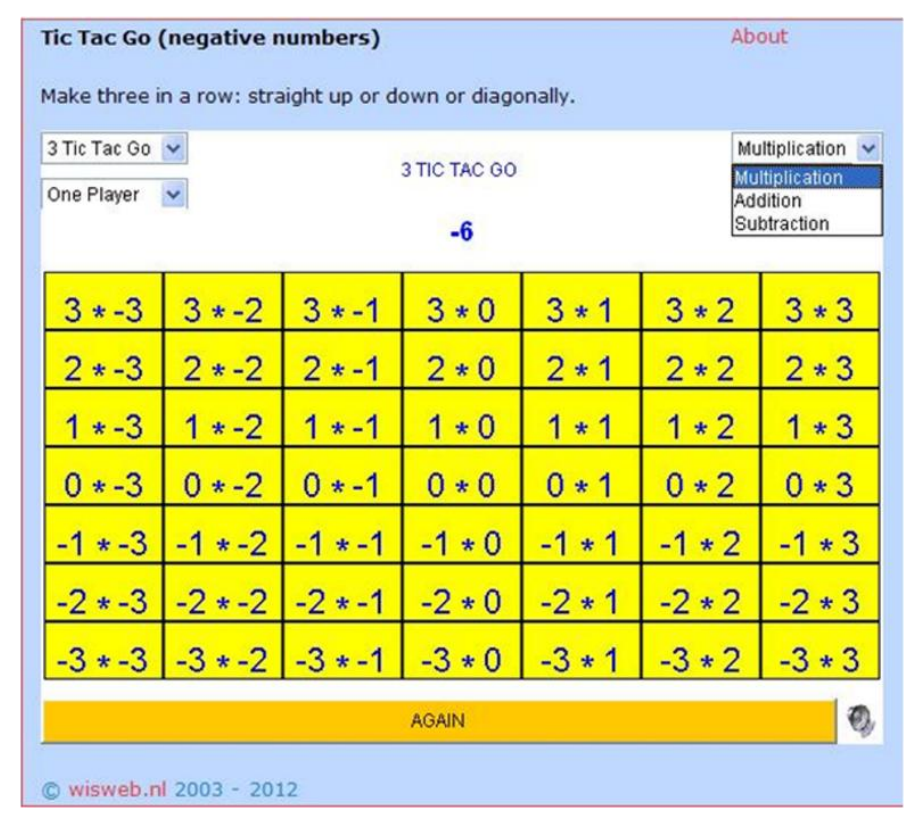

Figure 8: Tic Tac Go software.

The technological modernization of algebra teaching, points to a shift from memorization to meaningful mathematical action that leads to the development of initiative and decision making (Yerushalmy, 2006). The visual and numerical benefit gained from using computers and graphing calculators to work with symbolic expressions can help students give meaning to algebraic expressions and equations (Kilpatrick et al., 2001).

The teacher group identified Árvores Algébricas (Algebra Trees) and GeoGebra for working with algebraic expressions and GeoGebra and Raízes (Roots) for equations. The Árvores Algébricas (Algebra Trees) software, which was recommended for developing fluency with arithmetic expressions, can also be used with algebraic expressions and includes an option for graphing functions. When students first work with mathematical sentences that express equality, they need to understand that the equal sign represents a relation between quantities and is not a symbol indicating that a calculation must be performed. Activities are necessary that involve recognizing equalities such as $4+3=5+2$ and not just $4+3=7$ and $5+2=7$ (Ontario Ministry of Education, 2013). The teacher group observed that the Árvores Algébricas (Algebra Trees) software can assist with this type of activity. In this software, students recognize the equality between the expressions $4+3=5+2$ (Figure 9) when performing the operations $4+3=7$ and $5+2=7$ (Figure 10) by successively selecting the options "Expressão" (Expression) and "Valor" (Value). 


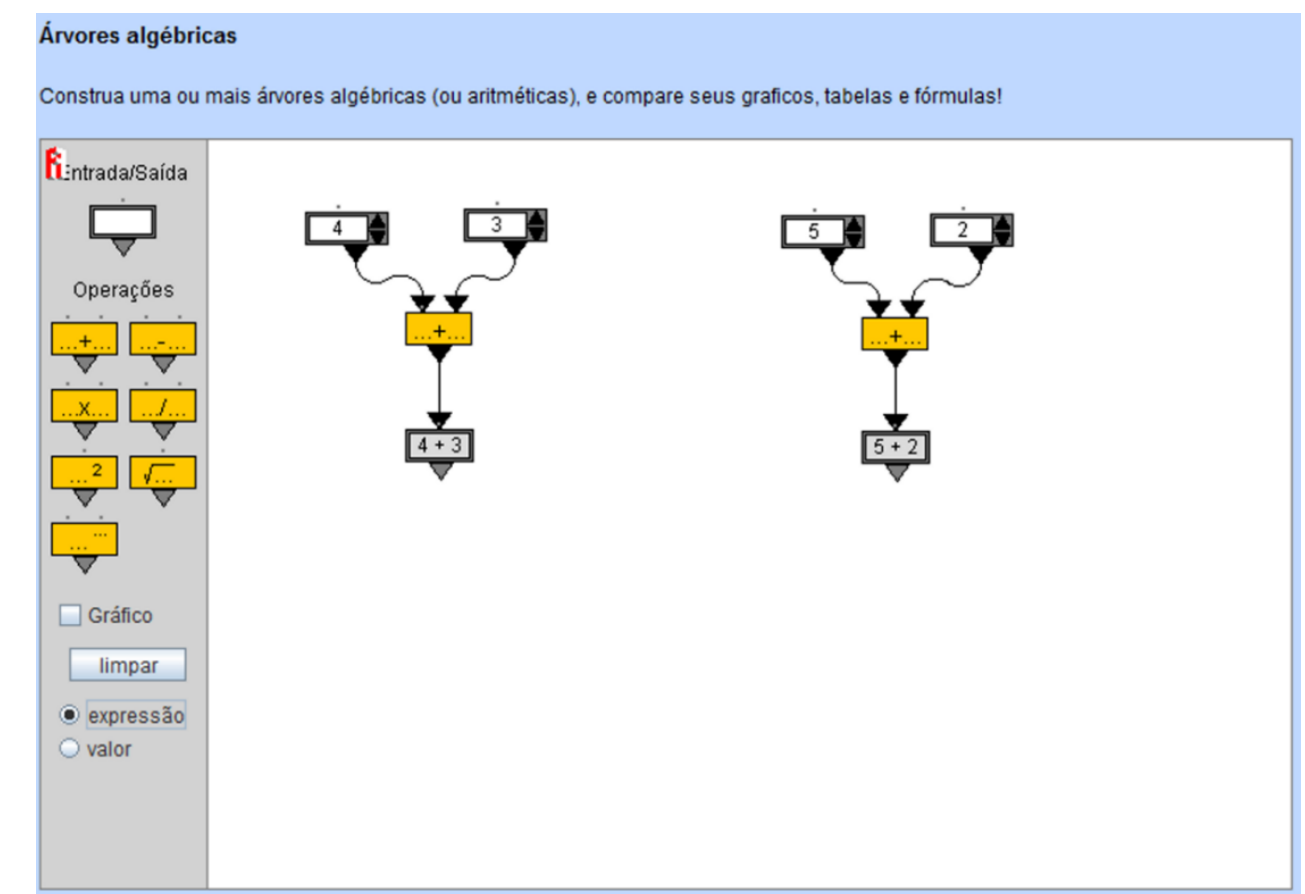

Figure 9: The "Expressão" (Expression) option in Árvores Algébricas (Algebra Trees) software.

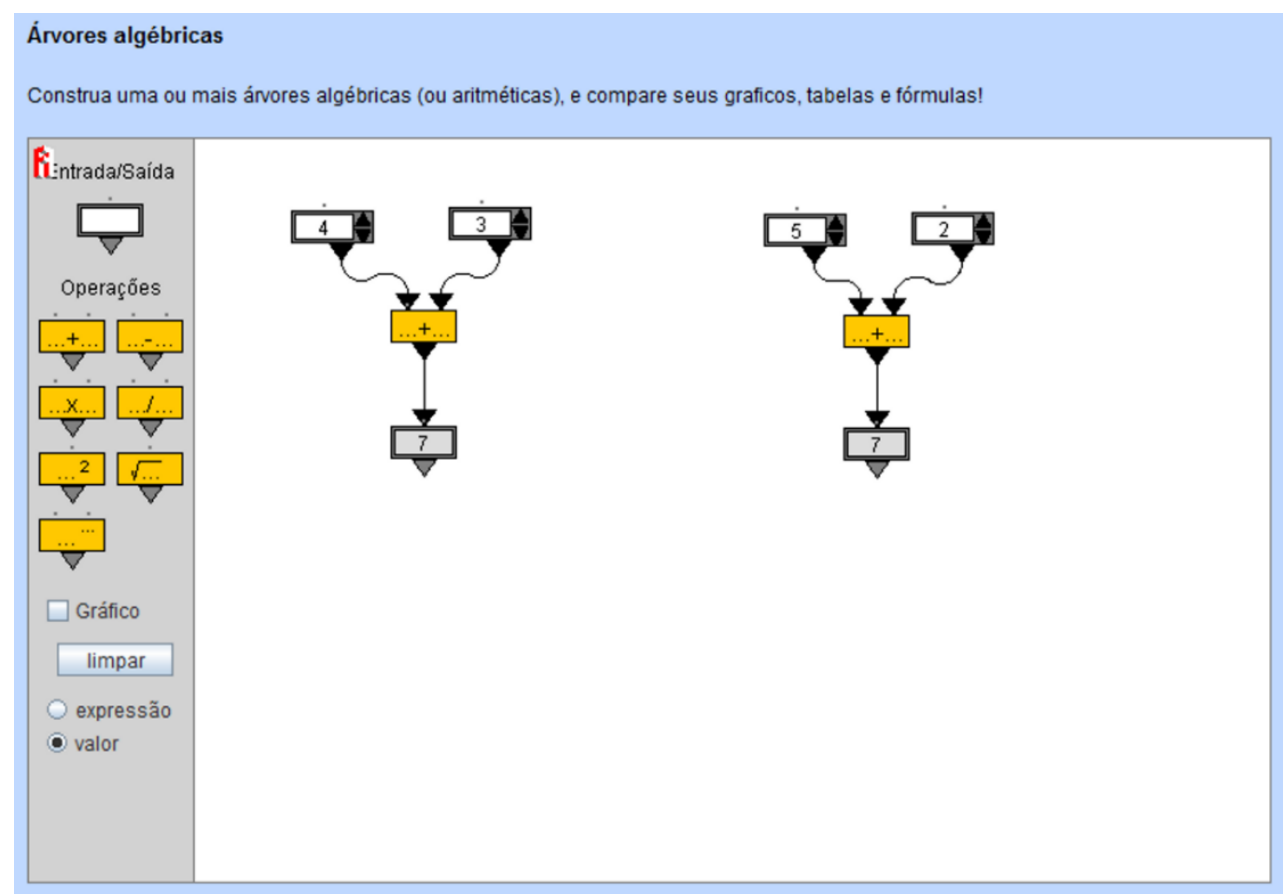

Figure 10: The "Valor" (Value) option in Árvores Algébricas (Algebra Trees) software.

When students calculate the roots of equations, most errors arise from using the quadratic formula (Didis \& Erbas, 2015). The Raízes (Roots) application displays empty boxes where the coefficients $\mathrm{a}, \mathrm{b}$ and c can be entered. The "Calcular" (Calculate) button returns either the roots of the equation or a message "Sem raízes reais" (No real roots). Students can also use the software to calculate the root of a linear equation by simply setting the coefficient of $x 2$ (i.e. a) to zero. 
Once students understand how to solve linear equations, the concept can then be extended to systems of equations (i.e. two linear equations sharing the same two variables). According to the Georgia Department of Education (2015), this process should start with systems whose solutions are ordered pairs of integers. This makes it easier to locate the intersection of the graphed equations and simplifies the calculations. More complex systems are then investigated and solved using graphing technologies. CCSSI (2010) and the Georgia Department of Education (2015) recommend that in addition to solving systems of linear equations algebraically, students also estimate solutions by graphing the equations. For graphing linear systems, our group of teachers identified GeoGebra, Grapher, Graph, MathGV and Winplot. Each of these applications allows users to simultaneously graph multiple equations and estimate whether the system has one, zero, or infinite solutions (for concurrent, parallel, or coincident lines, respectively).

Although Algebra is historically rooted in the study of general methods of solving equations, the principles advocated by NCTM (2000) emphasize the need to work with relationships between quantities, including functions, which are ways of representing mathematical relationships. This same document recommends that the focus in middle school should be on linear functions (rather than non-linear functions) and that these can be demonstrated via tables, graphs, or equations. The teachers identified GeoGebra, Geonext, GrafEq, Grapher, Graph, MathGV, SpeQ Mathematics and Winplot for working with 1st and 2nd degree polynomial functions. One important feature that these applications share is the ability to introduce functions and their properties while observing graphical and tabular representations of their domains and ranges. According to Chen et al. (2015), the understanding of different conversion processes for representing mathematics, increases the understanding of the mathematical concepts involved.

The software GeoGebra GeoGebra has been accepted in the teaching of mathematics for the teaching of Geometry as well as for Algebra (Mingirwa, 2016). GeoGebra not only provides the dynamic geometry features (Cardoso, Nogueira, Figueira-Sampaio, Santos \& Carrijo, 2013), but also shows both an algebraic and a graphical representation of each mathematical object, which is a useful feature for the study of algebra. The software also allows students to find the roots of functions. If users change an object in one representation, the other representation is immediately updated. Furthermore, the "View" button displays, it a spreadsheet with ordered pairs that correspond to coordinates on the graph within the domain of the function.

Our teacher group noted that many of the applications give students the opportunity to check their answers and discover their mistakes. Feedback on correct and incorrect actions allows students to correct themselves (Way, 2011) immediately and then attempt more effective strategies (Hattie \& Timperley, 2007). This in turn, allows students to rebuild concepts (Allen, 2007). 
Inequalities, notable products, and algebraic fractions are essential to mathematics education at the elementary/middle school level (Brasil, 1998; NCTM, 2000). However, none of the analyzed software offered features or resources that could help in the development of this content.

\section{Conclusion}

Numerical understanding encompasses the ability to deal with numbers and solve problems. Our map of free software identified viable options for developing and consolidating concepts related to the number system, operations and properties of natural and whole numbers, numeric expressions, divisibility, prime numbers, decomposition into prime factors, GCD, LCM, operations with rational numbers in fraction and decimal form, comparison and operations on equivalent fractions, first degree equations, and first and second degree polynomial functions. Our map lists some content that was not covered by any of the analyzed software.

The software interfaces are simple and intuitive and some of the applications can be configured for different languages. The universality of mathematics characters and symbols makes it easy to use the software in any of the available languages. In some cases, activities can be performed either on paper while others require rapid responses that can only be accomplished mentally.

In content areas where more than one application is available, software selection should consider the didactic-pedagogical requirements of the teacher and the technical requirements of the computer laboratory.

The software and mapping content feature relationship facilitates the selection of the resource in the planning of the teaching practice. The teacher develops their activities around the resources that aid the student in their understanding of mathematics, in developing computational fluency and in acquiring a positive attitude in terms of mathematics.

In terms of possible future work, it would be pertinent to consider the use of educational software in the teaching of mathematics to (a) validate the numerical concepts and procedures indicated by educators for each software, (b) evaluate the efficiency of software implementation for numerical and algebraic learning. Finally, (c) develop and validate strategies and/or material with the use of software for numeric and algebraic content.

\section{Acknowledgements}

The authors are grateful for financial support from the following Brazilian agencies: Fundação de Amparo à Pesquisa do Estado de Minas Gerais (FAPEMIG) and Coordenação de Aperfeiçoamento de Pessoal de Nível Superior (CAPES). 


\section{References}

Adjiage, R., \& Pluvinage, F. (2007). An experiment in teaching ratio and proportion. Educational Studies in Mathematics, 65(2), 149-175. doi:10.1007/s10649-006-9049-x

Ahn, B. (2001). Using calculators in mathematics education in Korean elementary schools. Journal of the Korea Society of Mathematical Education Series D: Research in Mathematical Education, 5(2), 107-118.

Allen, G. D. (2007). Student thinking. Lesson 1 - Misconceptions in mathematics. College Station, TX: Department of Mathematics. Retrieved from http://www.math.tamu.edu/ snite/MisMath.pdf

Amato, S. A. (2005). Developing students' understanding of the concept of fractions as numbers. In H. L. Chick, \& J. L. Vincent (Eds.). Proceedings of the 29th Conference of the International Group for the Psychology of Mathematics Education (pp. 49-56). Melbourne, Australia: PME.

Balanskat, A., Blamire, R., \& Kefala, S. (2006). The ICT impact report: A review of studies of ict impact on schools in Europe. Brussels, Belgium: European Schoolnet.

Beyranevand, M. L. (2014). The different representations of rational numbers. Mathematics Teaching in the Middle School, 19(6), 382-385. doi:10.5951/mathteacmiddscho.19.6.0382

Bezuk, N. S., \& Bieck, M. (1993). Current research on rational numbers and common fractions: Summary and implications for teachers. In D. T. Owens (Ed.), Research ideas for the classroom - middle grades mathematics (pp. 118 - 136). New York, NY: Macmillan.

Brasil (1998). Parâmetros curriculares nacionais: Matemática. Brasília, Brazil: MEC/Secretaria de Educação Fundamental.

Brown, A., Thomas, K, \& Tolias, G. (2002). Conceptions of divisibility: Success and understanding. In S. R. Campbell, \& R. Zazkis (Eds.), Learning and teaching number theory: Research in cognition and instruction (pp. 41-82). Westport, CT: Ablex.

Cardoso, M. C. S. A., Nogueira, T. C. A., Figueira-Sampaio, A. S., Santos, E. E. F., \& Carrijo, G. A. (2013). Software gratuitos de geometria dinâmica. In J. Sánchez, \& M. B. Campos (Eds.). Nuevas ideas em informática educativa. Actas del Congreso Internacional de Informática Educativa (pp. 515-518). Santiago, Chile: Universidad de Chile.

Chen, M., Lee, C., \& Hsu, W. (2015). Influence of mathematical representation and mathematics self-efficacy on the learning effectiveness of fifth graders in pattern reasoning. International Journal of Learning, Teaching and Educational Research, 13(1), 1-16.

Common Core State Standards Initiative (2010). Common core state standards for mathematics. Retrieved from http://www.corestandards.org/Math/

Condie, R., Munro, B., Seagraves, L., \& Kenesson, S. (2007). The impact of ICT in schools A landscape review. Glasgow, Scotland: University of Strathclyde.

Crandall, R., \& Pomerance, C. (2005). Prime numbers: A computational perspective (2nd edition). New York, NY: Springer.

Debnath, L., \& Basu, K. (2015). Some analytical and computational aspects of prime numbers, prime number theorems and distribution of primes with applications. International Journal of Applied and Computational Mathematics, 1(1), 3-32. doi: 10.1007/s40819-014-0014-6

Dias, A. (2005). Using lattice models to determine Greatest Common Factor and Least Common Multiple. International Journal for Mathematics Teaching and Learning, 730-738.

Didis, M. G., \& Erbas, A. K. (2015). Performance and difficulties of students in formulating and solving quadratic equations with one unknown. Educational Sciences: Theory \& Practice, 15(4), 1137-1150. doi: 10.12738/estp.2015.4.2743 
Dunphy, E., Dooley, T., Shiel, G, Butler, D., Corcoran, D., Ryan, M., ... Perry, B. (2014). Mathematics in early childhood and primary education (3-8 years): Definitions, theories, development and progression. (Research Report no. 17). Dublin, Ireland: NCCA.

Figueira-Sampaio, A. S., Santos, E. E., Carrijo, G. A., \& Cardoso, A. (2012). Survey of teaching practices with educational software for mathematics in Brazil. AWER Procedia Information Technology \& Computer Science, 2, 358-363.

Figueira-Sampaio, A. S., Santos, E. E., Carrijo, G. A., \& Cardoso, A. (2013). Survey of mathematics practices with concrete materials used in Brasizilian schools. Procedia - Social and Behavioral Sciences, 93, 151-157. doi: 10.1016/j.sbspro.2013.09.169

Fuadiah, N. F. (2015). Epistemological obstacles on mathematic's learning in junior high school students: A study on the operations of integer material. In Proceeding of the 2nd International Conference on Research, Implementation and Education of Mathematics and Sciences (ICRIEMS 2015) (pp. 315-322). Yogyakarta, Indonésia: Faculty of Mathematics and Science, Yogyakarta State University.

Georgia Department of Education (2015). Georgia standards of excellence framework GSE Grade 8: Mathematics: Unit 7: Solving systems of equations. Retrieved from https://www.georgiastandards.org/Georgia-Standards/Frameworks/8thMath-Unit-7.pdf

Hattie, J., \& Timperley, H. (2007). The power of feedback. Review of Educational Research, 77(1), 81-112.

Heeffer, A. (2008). Negative numbers as an epistemic difficult concept: Some lessons from history. In: C. Tzanakis (Ed.). Proceedings of the History and Pedagogy of Mathematics Conference (pp. 1-13). Mexico City, Mexico: Centro Cultural del México Contemporáneo.

Isotani, S., McLaren, B. M., \& Altman, M. (2010). Towards intelligent tutoring with erroneous examples: A taxonomy of decimal misconceptions. In V. Aleven, J. Kay, \& J. Mostow (Eds.). Proceedings of the 10th International Conference on Intelligent Tutoring Systems (ITS-10), Lecture Notes in Computer Science, 6094 (pp. 346-348). Heidelberg, Germany: Springer. doi: 10.1007/978-3-642-13437$1 \_66$

Kar, T., \& Işık, C. (2015). Comparison of turkish and american seventh grade mathematics textbooks in terms of addition and subtraction operations with integers. Education \& Science, 40(177), 75-92. doi: 10.15390/eb.2015.2897

Keong, C., H. Sharaf, H., \& Daniel, J. (2005). A study on the use of ICT in mathematics teaching. Malaysian Online Journal of Instructional Technology, 2(3), 43-51.

Kilpatrick, J., Swafford, J., \& Findell, B. (2001). Adding it up: Helping children learn mathematics. Washington, DC: National Academy Press.

Lee, K. P. (2006). Calculator use in primary schools mathematics: a Singapore perspective. The Mathematics Educator, 9(2), 97-111.

Lemonidis, C., \& Kaiafa, I. (2014). Fifth and sixth grade students' number sense in rational numbers and its relation with problem solving ability. Journal of Educational Research, (1), 61-74.

Lengnink, K., \& Schlimm, D. (2010). Learning and understanding numeral systems: Semantic aspects of number representations from an educational perspective. In B. Löwe, \& T. Müller (Eds.), Philosophy of mathematics: Sociological aspects and mathematical practice (pp. 235-264). London, England: College Publications.

Lewis, L. (2007). Irrational numbers can "in-spiral" you. Mathematics Teaching in the Middle School, 2(8), 442-446.

Lundberg, A. (2011). Proportion in mathematics textbooks in upper secondary school. In M. Pytlak, \& T. Rowland, \& E. Swoboda (Eds.). Proceedings of the Seventh Congress of the European Society for Research in Mathematics Education (pp 336-345). Rzeszów, Polonia: University of Rzeszów. 
Mingirwa, I. M. (2016). Teachers' technology uptake, a case of GeoGebra in teaching secondary school mathematics in Kenya. In P. Cunningham, \& M. Cunningham (Eds). Proceedings of International Information Management Corporation (IIMC) (pp. 1-11), Durban, South Africa: IST-Africa.

Mohamed, M., \& Johnny, J. (2010). Investigating number sense among students. ProcediaSocial and Behavioral Sciences, 8, 317-324. doi: 10.1016/j.sbspro.2010.12.044

National Council of Teachers of Mathematics. (2000). Principles and standards for school mathematics. Reston, VA: National Council of Teachers of Mathematics.

Neurath, R. A., \& Stephens, L. J. (2006). The effect of using Microsoft Excel in a high school algebra class. International Journal of Mathematical Education in Science and Technology, 37(6), 721-727.

$\mathrm{Ni}$, Y. (2001). Semantic domains of rational numbers and the acquisition of fraction equivalence. Contemporary Educational Psychology, 26(3), 400-417. doi: 10.1006/ceps.2000.1072

Nunes, T., \& Bryant, P. (2009). Understanding rational numbers and intensive quantities. In T. Nunes, P. Bryant, \& A. Watson (Eds.), Key understanding in mathematics learning (Paper 3, pp. 19-23). London, England: Nuffield Foundation.

Ontario Ministry of Education (2005). The Ontario curriculum: Grades 1-8 mathematics. Toronto, ON: Queen's Printer for Ontario.

Ontario Ministry of Education (2012). Paying attention to proportional reasoning K-12. Support document for paying attention to mathematical education. Toronto, ON: Queen's Printer for Ontario.

Ontario Ministry of Education (2013). Paying attention to algebraic reasoning K-12. Support document for paying attention to mathematical education. Toronto, ON: Queen's Printer for Ontario.

Ontario Ministry of Education (2014). Paying attention to fractions K-12. Support document for paying attention to mathematical education. Toronto, ON: Queen's Printer for Ontario.

Peretti, A. (2015). Some notes on divisibility rules. Working Paper Series. Department of Economics. University of Verona. Retrieved from http://dse.univr.it/home/workingpapers/wp2015n19.pdf

Reynolds, C. R., \& Fletcher-Janzen, E. (2007). Encyclopedia of special education: A reference for the education of children, adolescents, and adults with disabilities and other exceptional individuals. Hoboken, NJ: John Wiley \& Sons, Inc.

Sadi, A. (2007). Misconceptions in Numbers. UGRU Journal, 5, 1-7.

Savion, H. \& Seri, M. (2016). Mathematics vis-à-vis arithmetics. International Journal of Learning, Teaching and Educational Research, 15(2), 1-18.

Seeley, C. (2005). Do the math in your head! National Research Council. NCTM News Bulletin. Retrieved from http://www.nctm.org/News-and-Calendar/Messagesfrom-the-President/Archive/Cathy-Seeley/Do-the-Math-in-Your-Head!/

Silvestre, A. I., \& Ponte, J. P. (2012). Missing value and comparison problems: What pupils know before the teaching of proportion. PNA, 6(3), 73-83.

Sirotic, N., \& Zazkis, R. (2007). Irrational numbers on the number line - where are they? International Journal of Mathematical Education in Scienceand Technology, 38(4), 477488. doi: 10.1080/00207390601151828

Smith, J., \& Thompson, P. W. (2007). Quantitative reasoning and the development of algebraic reasoning. In J. J. Kaput, D. W. Carraher \& M. L. Blanton (Eds.), Algebra in the early grades (pp. 95-132). New York, NY: Erlbaum.

Stacey, K., Helme, S., Steinle, V., Baturo, A., Irwin, K., \& Bana, J. (2001). Preservice Teachers' Knowledge of Difficulties in Decimal Numeration. Journal of Mathematics Teacher Education, 4(3), 205- 225. 
Stafylidou, S., \& Vosniadou, S. (2004). The development of students' understanding of the numerical value of fractions. Learning and Instruction, 14(5), 503-518. doi: 10.1016/j.learninstruc.2004.06.015

Star, J. R., Caronongan, P., Foegen, A. M., Furgeson, J., Keating, B., Larson, M. R, ... Zbiek, R. M. (2015). Teaching strategies for improving algebra knowledge in middle and high school students. Washington, DC: National Center for Education Evaluation and Regional Assistance (NCEE), Institute of Education Sciences, U.S. Department of Education.

Thanheiser E., Whitacre, I., \& Roy, G. J. (2014). Mathematical content knowledge for teaching elementary mathematics: A focus on whole-number concepts and operations. The Mathematics Enthusiast, 11(2), 217-266.

Van Hoof, J., Verschaffel, L., \& Van Dooren, W. (2015). Inappropriately applying natural number properties in rational number tasks: Characterizing the development of the natural number bias through primary and secondary education. Educational Studies in Mathematics, 90(1), 39-56. doi: 10.1007/s10649-015-9613-3

Voskoglou, M. Gr., \& Kosyvas, G. (2011). A study on the comprehension of irrational numbers. Quaderni di Ricerca in Didattica (Scienze Mathematiche), (21), 127-141.

Way, J. (2011). Developing fraction sense using digital learning objects. In J. Way, \& J. Bobis (Eds.), Fractions: Teaching for understanding (pp. 153-166). Adelaide, SA: Australian Association of Mathematics Teachers.

Yerushalmy, M. (2006). Slower algebra students meet faster tools: Solving algebra word problems with graphing software. Journal for Research in Mathematics Education, 37(5), 356-387.

Zazkis, R., \& Sirotic, N. (2010). Representing and defining irrational numbers: Exposing the missing link. In F. Hitt, D. Holton, \& P. W. Thompson (Eds.), Research in collegiate mathematics education VII (pp. 1-27). Rhode Island, USA: American Mathematical Society. doi: 10.1090/cbmath/016/01 